\title{
Representatividade da Biologia em CTS Por Meio de Análise por Redes Sociais
}

\author{
Milena Lopes da Rocha ${ }^{1}$ \\ Ana Helena Grieco Gonzalez ${ }^{2}$ \\ Natália Vinhosa Bruno 3 \\ Álvaro Chrispino ${ }^{4}$
}

\begin{abstract}
Resumo
0 presente trabalho buscou investigar como as temáticas relacionadas ao Ensino de Biologia são representadas nos estudos em Ciência, Tecnologia e Sociedade (CTS). Os textos analisados na pesquisa foram obtidos no Banco de Dados do Grupo CTS e Educação, do Cefet/ RJ. Para a obtenção dos artigos relacionados à temática pesquisada, foram selecionados, dentre os 173 trabalhos e 632 palavras-chave sobre Ensino CTS, aqueles que continham termos considerados de grande importância na área de Biologia/Ensino de Biologia, presentes no Título, Resumo ou Palavras-chave. Mediante a Análise de Rede Social os dados foram analisados quanto às temáticas abordadas - por meio da análise das palavras-chave - e quanto ao referencial metodológico utilizado, e pela análise dos principais autoresltrabalhos citados. Os resultados desta investigação auxiliam a compreender como a biologia vem sendo representada no campo de CTS, as temáticas de pesquisa, assim como a conhecer os principais autores citados nesta área. Os resultados obtidos demonstram uma particularidade da subárea de biologia ao comparar com o campo de CTS no Brasil. Concluiu-se que esta se apropria da abordagem de CTS em suas pesquisas, porém, não utiliza plenamente as referências que são tidas como base comum na ampla área de Ensino CTS, utilizando, assim, referenciais teóricos peculiares.
\end{abstract}

Palavras-chave: CTS. CTSA. Ensino de Biologia. Redes sociais.

1 Mestranda do Programa de Pós-Graduação em Ciência, Tecnologia e Educação do Cefet-RJ. milenalrocha@yahoo.com.br

2 Mestranda do Programa de Pós-Graduação em Ciência, Tecnologia e Educação do Cefet-RJ. anahelenagg@hotmail.com

3 Mestranda do Programa de Pós-Graduação em Ciência, Tecnologia e Educação do Cefet-RJ. naty_vbruno@yahoo.com.br

${ }^{4}$ Doutor em Educação/UFRJ e professor dos Programas de Pós-Graduação do Cefet-RJ. alvaro. chrispino@gmail.com 


\section{Abstract}

The present study aims to investigate how themes related to the Teaching of Biology are represented by the studies in Science, Technology and Society (STS). The papers analysed were obtained from the STS Group and Education Database of Cefet/RJ - Brazil. In order to obtain the articles related to the research theme, amongst the 173 papers and 632 keywords about STS Teaching, were selected those containing terms considered of great importance in the Biology/Biology Teaching field, present in the title, abstract or keywords. Through the Social Network Analysis, the data were analysed regarding the themes addressed - through the analysis of the keywords - and the methodological reference used, by the analysis of the main authorslworks referenced. The results help to understand how biology is represented in the STS field, their research themes, as well as the main authors referenced. The results demonstrate a particularity of the biology subarea when compared with the STS field in Brazil. It was concluded that, although this subarea uses the STS approach in its research, it does not utilize the references that are considered common basis in the wide area of STS Teaching, using, therefore, its own theoretical references.

Keywords: STS. STSE. Biology teaching. Social network. 
De acordo com Santos (2007), a cidadania tradicional acaba por menosprezar o cultivo dos saberes científicos, sendo este um fator importante para que se tenha uma cidadania atuante e bem-informada. Na atualidade, as sociedades vêm sofrendo com grandes problemas socioambientais em âmbitos locais e globais, o que torna urgente a necessidade de mudar a cidadania moderna para uma cidadania pós-moderna, tendo como foco a cidadania ambiental.

As relações entre Ciência, Tecnologia e Sociedade (CTS), complexificadas pelo acelerado desenvolvimento tecnológico e científico, se ampliam na sociedade pós-moderna, ganhando importância a sua compreensão. Entender as relações de CTS, dentre muitos aspectos, envolve um olhar crítico para o papel da ciência e da tecnologia na sociedade, com a percepção da ciência como uma atividade socialmente comprometida, desprovida de neutralidade, uma vez que financiamentos se destinam para determinados interesses e conhecimentos e o questionamento do modelo linear de desenvolvimento tecnológico. O que se pretende com os estudos de CTS é trazer a discussão das implicações tecnocientíficas para o contexto social, buscando meios para que a sociedade possa participar democraticamente na indicação dos seus rumos; afinal, uma sociedade que não discute tais implicações sofre com as ações e consequências, ficando a reboque dos tomadores de decisão. Daí a importância da democratização dos saberes como geradora de informação e motivação para a participação cidadã (CHRISPINO et al., 2013).

Dessa maneira, educar, numa perspectiva de CTS, é, fundamentalmente, possibilitar uma formação para maior inserção social das pessoas no sentido de se tornarem aptas a participar dos processos de tomadas de decisão conscientes e negociadas em assuntos que envolvam ciência e tecnologia (VON LINSINGEN; CASSIANI 2011). Assim, falar de CTS é fazer referência tanto a fatores sociais que influenciam diretamente mudanças científico-tecnológicas, quanto a consequências sociais e ambientais, podendo-se fazer uma análise do modelo de tecnologia instituído. $\mathrm{O}$ que se pretende é fornecer subsídios concretos à população para que adquira uma postura ativa e coerente na transformação da sociedade, levando em consideração o enviesamento de postura em relação à solução que se considera racional, posto que crenças e valores pessoais influenciam significativamente nas tomadas de decisão. Afinal, o que vemos e fazemos no mundo parte de nossos princípios e concepções (ACEVEDO et al., 2005). 
A forma mais viável de alcançar estas mudanças consideradas necessárias é trazer para o ensino, em todos os níveis, discussões a respeito da ciência e tecnologia, partindo de um entendimento mais crítico e contextualizado das consequências de ações antrópicas sobre o meio em que se vive. Dessa forma, proporciona-se ao cidadão maior embasamento para participação nas tomadas de decisão com base nos fundamentos das relações de CTS. Nesse sentido, é fundamental a orientação do docente sobre a construção do conhecimento científico, processo que agrega valor a todos os atores sociais, estando estes diretamente envolvidos na transformação da realidade. Para Acevedo, Vázquez e Manassero (2003), são necessárias duas ações básicas para viabilizar essa inovação do papel docente: suscitar uma profunda reflexão sobre o que realmente se constitui como fundamental no ensino de ciências para o século 21 , e garantir uma formação de qualidade para os professores sobre o movimento de CTS, sob o ponto de vista de uma inovação educativa capaz de propiciar uma alfabetização científica e tecnológica útil para todas as pessoas. Vemos em Von Linsingen (2007) a relevância da educação escolar na preparação de indivíduos para uma convivência intercultural sem a perda de suas identidades, favorecendo a compreensão de mudanças da identidade nesse contato de diferentes culturas. Essa educação escolar não é moldada em um único jeito de acontecer, principalmente tendo em vista que o processo educacional ocorre em vários momentos e espaços, não apenas na escola formal.

Em decorrência dos problemas ambientais agravados a partir da industrialização e adensamentos populacionais, surgiram outras propostas de ensino, entre as quais a educação Ciência-Tecnologia-Sociedade-Ambiente (CTSA): estudo pertencente à CTS com enfoque no meio ambiente. Pensar em uma educação ambiental é pensar em uma reapropriação de valores ligados à solidariedade, às ações coletivas, ou seja, a uma ecologia da subjetividade, o que vem na contramão do que está caracterizado como desenvolvimento social e econômico ao longo do nosso processo histórico. Em Grün (2011), vemos que diversos autores relacionam a crise ecológica vivida atualmente como decorrência das práticas do homem. Desta forma, uma abordagem a respeito dos valores que regem o agir humano em sua relação com a natureza é de fundamental importância. 
Talvez mais do que criar "novos valores", a educação ambiental deveria se preocupar em resgatar alguns valores já existentes, mas que foram recalcados ou reprimidos pela tradição dominante do racionalismo cartesiano (GRÜN, 2011, p. 23).

Esta reflexão nos ajuda a compreender de que forma os valores vão se cristalizando e, neste sentido, como os desafios de mudança passam pela formação da criança, do jovem e, consequentemente, da escola na construção de uma cidadania implicada com um novo modo de produção da vida. Grün (2011) ainda acrescenta que, tendo em vista a era antropocêntrica vivida nos dias atuais, redescobrir valores sufocados pelo pensamento científico moderno, em que há a predominância do homem sobre todas as coisas do mundo, favorece, acima de tudo, um pensamento sobre a vida, a existência dos seres e a real importância de seus vínculos.

O ensino de ciências tem como foco as relações dos seres humanos entre si e destes com a natureza, trazendo como principal preocupação a sustentabilidade da vida. Os currículos de ensino de ciências vêm sendo modificados com a inclusão do enfoque de CTS/CTSA e, segundo Andrade e Vasconcelos (2014), as transformações que envolvem a sociedade, o ambiente e os aspectos científico-tecnológicos têm sido o ponto de partida de algumas propostas voltadas para o ensino de Biologia, mais especificamente a abordagem de CTSA.

Tendo em vista a crescente importância a respeito de CTS/CTSA, o presente trabalho busca estabelecer um panorama inicial da temática Biologia/ Meio Ambiente dentro dos Estudos de CTS na área de ensino no Brasil, mediante análise das principais palavras-chave e dos referenciais teóricos mais utilizados na área.

\section{Metodologia}

A coleta dos dados foi realizada no Banco de Dados do Grupo CTS e Educação, do Cefet/RJ. O Banco de Dados é constituído por publicações brasileiras encontradas em 31 revistas da área de Ensino, indexadas pelo Qualis, publicadas até o ano de 2014. Todas possuem um sistema digital e gratuito de acesso. Os artigos que compõem o Banco de Dados foram selecionados a partir da busca 
pelas palavras "Ciência", "Tecnologia" e "Sociedade", juntas ou separadas, nos campos Título, Resumo ou Palavras-chave. Identificada a relação com a temática de CTS, todas as informações referentes ao artigo (ano de publicação, periódico, autores, instituições, título, palavras-chave e referências) foram catalogadas. O Banco de dados contém 173 artigos, 632 palavras chaves e 3.990 referências bibliográficas. A seguir, segue a listagem das revistas contempladas no Banco de Dados (Tabela 1):

Tabela 1 - Listagem das revistas que compõem o Banco de Dados

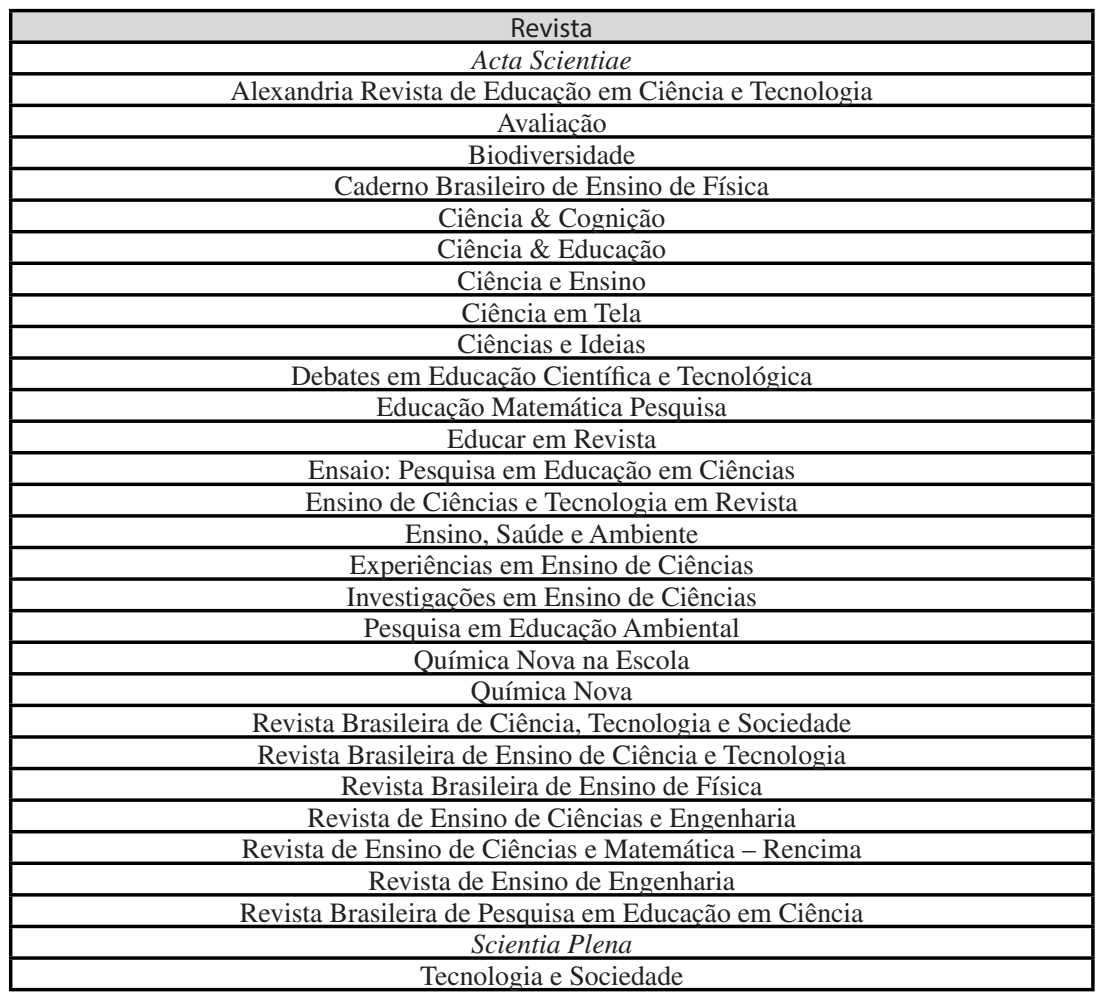

Para este trabalho foi realizada uma segunda seleção de artigos dentro do Banco de Dados, buscando aqueles ligados à temática investigada, que continham as seguintes palavras e expressões em seu título, resumo ou palavras-chave: "Biologia", "Ensino de biologia", "CTSA", "Sustentabilidade", 
"Educação ambiental", "Meio ambiente", "Biodiversidade", "Ecossistema", "Ambientalismo", "Ensino de biologia". Os 45 trabalhos encontrados na busca foram analisados quanto às palavras-chave encontradas - por meio da análise das temáticas - e quanto aos principais autores/trabalhos citados, discutindo o referencial metodológico utilizado.

A metodologia empregada para as análises das palavras-chave e dos trabalhos mais citados se baseia na Análise de Rede Social, que considera que os dados investigados compõem uma rede, estando interligados entre si. Para Matheus e Silva (2006), a diferença fundamental da Análise de Rede Social para outros estudos é que a ênfase não incide sobre os atributos (características) dos atores, mas sobre as ligações entre os elos; ou seja, a unidade de observação é composta pelo conjunto de atores e suas relações.

A fim de compreender como os integrantes da rede se relacionam, utilizam-se algumas métricas para melhor visualizar os principais participantes e conectores da rede. Para obter as redes (palavras-chave e referenciais teóricos) e gerar as métricas, utilizou-se o programa NodeXL, uma extensão do Excel. O programa auxilia na visualização dos padrões estruturais das redes e aponta as medidas de centralidade que determinam quais os elementos ou vértices são mais "centrais", aqueles que têm papel de destaque na comunicação da informação. Além do grau de entrada, que é o número de ligações de um vértice, isto é, quantidade de citações feitas, outras duas medidas foram consideradas para a análise das redes deste trabalho: a centralidade de intermediação e a centralidade de proximidade. A centralidade de intermediação, como o próprio nome indica, é responsável por medir quão importante é o vértice na intermediação entre as informações, uma vez que mede a frequência com que o vértice em questão está no menor caminho entre dois outros vértices. Quanto maior for o valor, maior será o grau de intermediação. A centralidade de proximidade é uma medida de distância entre os vértices que mede quais vértices poderiam chegar mais rapidamente a outros vértices da rede.

Após gerar as redes e obter as métricas supradescritas os resultados foram organizados em uma Tabela para posterior análise. Em virtude do grande número de vértices obtido, foi necessário determinar um corte para análise, cujo 
critério considerou os vértices de maior frequência na rede, ou seja, aqueles com maior grau de entrada. Para a análise das palavras-chave destacaram-se os 10 vértices mais frequentes. Para as referências, foram selecionadas as 15 obras mais citadas. $\mathrm{O}$ corte não foi o mesmo para as duas categorias pela necessidade de manter apenas aqueles com maior número de ligações.

\section{Resultados e Discussão}

A partir dos 45 trabalhos analisados obteve-se um total de 142 palavras-chave e 4.337 referências. As duas categorias de análise foram elencadas nas Tabelas 2 e 3, com as maiores frequências de ligações, conforme detalhado na metodologia. Na sequência das tabelas seguem as respectivas redes.

Tabela 2 - Palavras-chave mais frequentes

\begin{tabular}{|l|l|l|l|l|}
\hline Posição & Palavra-chave & $\begin{array}{l}\text { Grau de } \\
\text { entrada }\end{array}$ & $\begin{array}{l}\text { Centralidade de } \\
\text { intermediação }\end{array}$ & $\begin{array}{l}\text { Centralidade de } \\
\text { proximidade }\end{array}$ \\
\hline 1 & CTS & 42 & 1115,449 & 0,012 \\
\hline 2 & ENSINO DE CIÊNCIAS & 25 & 329,750 & 0,010 \\
\hline 3 & CTSA & 22 & 388,681 & 0,010 \\
\hline 4 & $\begin{array}{l}\text { ALFABETIZAÇÃO CIENTÍFICA } \\
\text { E TECNOLÓGICA }\end{array}$ & 14 & 99,261 & 0,009 \\
\hline 5 & INTERDISCIPLINARIDADE & 10 & 82,838 & 0,009 \\
\hline 6 & AMBIENTE & 9 & 31,240 & 0,008 \\
\hline 7 & EDUCAÇÃO & 9 & 63,230 & 0,008 \\
\hline 8 & ENSINO DE BIOLOGIA & 8 & 104,386 & 0,008 \\
\hline 9 & EDUCAÇÃO AMBIENTAL & 8 & 30,246 & 0,008 \\
\hline 10 & ENERGIA & 8 & 30,246 & 0,007 \\
\hline
\end{tabular}




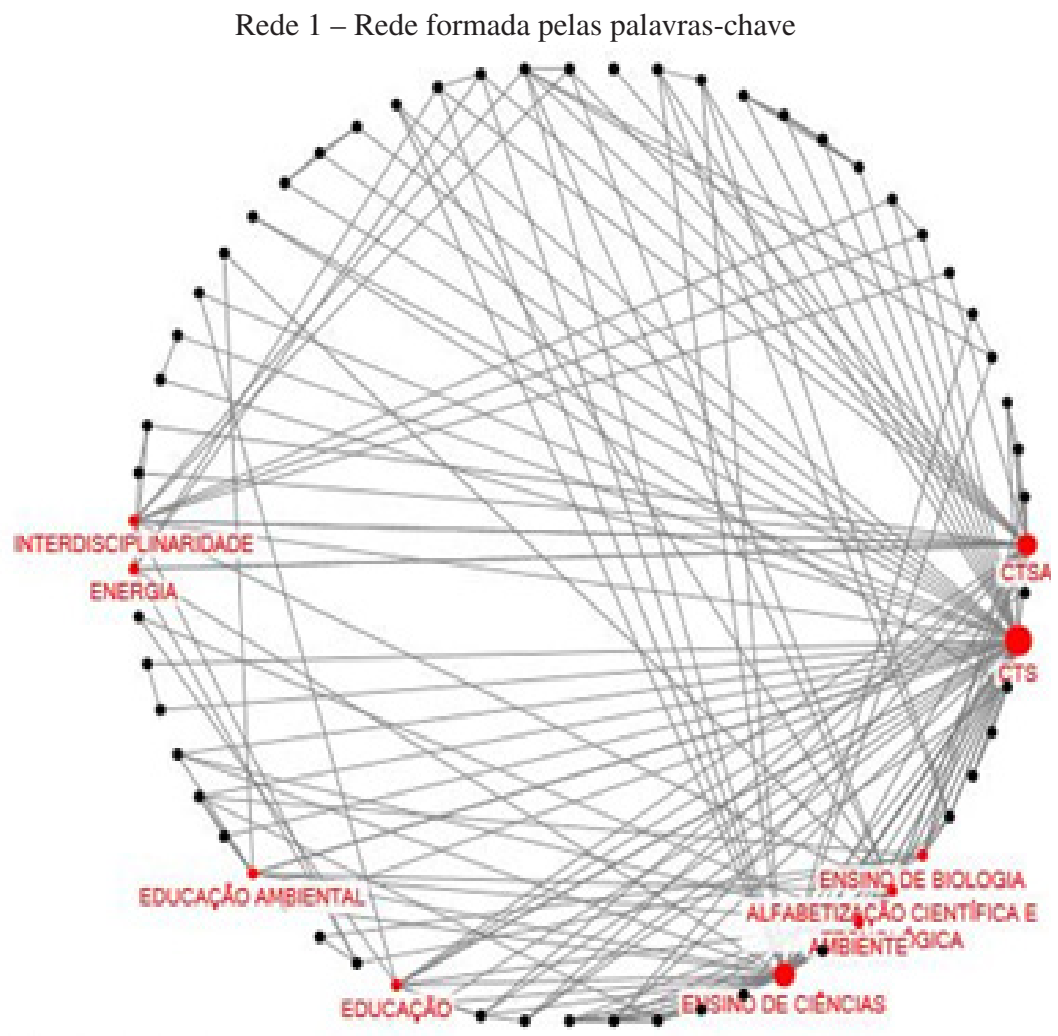

Created with NodeXL (httplinodexl.codeplex.com)

$\mathrm{O}$ resultado obtido com as palavras-chave mais frequentes permite inferir sobre as temáticas mais discutidas no tema pesquisado. Toledo et al. (2016) destacam a importância das palavras-chave como instrumentos de análise para os caminhos tomados por uma determinada área, como itens de busca para futuras pesquisas e como relações entre as temáticas das pesquisas acadêmicas. 
É de se esperar que a palavra-chave mais encontrada tenha sido o acrônimo "CTS", uma vez que o estudo foi realizado a partir do Banco de Dados resultante de pesquisa desde a área de CTS em Ensino e Educação. Destaca-se, com grande valor de centralidade de intermediação, o acrônimo "CTSA". Partindo do princípio de que este sugere um grau de interdisciplinaridade significativo, assim como de CTS, por englobar diversas áreas do saber, entende-se que, na esfera biológica/ambiental, esta sigla seja bastante utilizada por autores que publicam em temas correlatos ou próximos à CTSA. Assim, alguns termos que fazem parte da própria proposta da construção da área de educação de CTSA, como "ambiente", "alfabetização científica e tecnológica", "educação ambiental" e "energia", estão também presentes nesse universo de palavras-chave. De maneira geral, os dados mostram que, dentro da ampla área de ensino de CTS, a pesquisa em ensino de biologia vem sendo realizada com abordagem interdisciplinar, abarcando temáticas relacionadas à sustentabilidade, como educação ambiental e energia.

Um dado em destaque é a palavra-chave "Ensino de Biologia", que apresenta valor de centralidade de intermediação considerável. Isso revela que esse termo é de grande importância para o fluxo da informação na rede, isto é, ele é o caminho para que as demais palavras-chave possam interagir nessa rede. De maneira geral, esse dado também demonstra que o "Ensino de Biologia" vem sendo abordado de maneira ampla, abarcando diversas temáticas. 
Tabela 3 - Referências mais frequentes

\begin{tabular}{|l|l|c|}
\hline \multicolumn{1}{|c|}{ Autor } & \multicolumn{1}{|c|}{ Obra } & $\begin{array}{c}\text { n. de } \\
\text { Citações }\end{array}$ \\
\hline $\begin{array}{l}\text { SANTOS, W. L. P.; } \\
\text { MORTIMER, E. F. }\end{array}$ & $\begin{array}{l}\text { Uma análise de pressupostos teóricos da } \\
\text { abordagem C-T-S (Ciência-Tecnologia- } \\
\text { Sociedade) no contexto da educação brasileira }\end{array}$ & 13 \\
\hline DELIZOICOV, D. & Ensino de ciências: Fundamentos e métodos & 9 \\
\hline BRASIL & $\begin{array}{l}\text { Parâmetros Curriculares Nacionais Ensino } \\
\text { Médio }\end{array}$ & 8 \\
\hline $\begin{array}{l}\text { SANTOS, W. L. P.; } \\
\text { MORTIMER, E. F. }\end{array}$ & $\begin{array}{l}\text { Tomada de decisão para a ação social } \\
\text { responsável no ensino de ciências }\end{array}$ & 7 \\
\hline AIKENHEAD, G. & What is STS science teaching? & 7 \\
\hline FOUREZ, G. & $\begin{array}{l}\text { Alfabetizacion científica e tecnológica - acerca } \\
\text { de las finalidades de la enseñanza }\end{array}$ & 7 \\
\hline $\begin{array}{l}\text { AULER, D.; } \\
\text { DELIZOICOV, D. }\end{array}$ & Alfabetização científico-tecnológica para quê? \\
\hline $\begin{array}{l}\text { SANTOS, W. L. P.; } \\
\text { SCHNETZLER, R. P. }\end{array}$ & $\begin{array}{l}\text { Educação química: Compromisso com a } \\
\text { cidadania }\end{array}$ & 7 \\
\hline CHASSOT, A. I. & $\begin{array}{l}\text { Alfabetização científica: questões e desafios } \\
\text { para a educação }\end{array}$ & 6 \\
\hline TEIXEIRA, P.M.M. & $\begin{array}{l}\text { A educação científica sob a perspectiva da } \\
\text { pedagogia histórico-crítica e do movimento } \\
\text { C.T.S. no ensino de ciências }\end{array}$ & 6 \\
\hline $\begin{array}{l}\text { LÜDKE, M.; ANDRÉ, } \\
\text { M. E. D. A. }\end{array}$ & Pesquisa em Educação: abordagens qualitativas & 6 \\
\hline BRASIL & $\begin{array}{l}\text { Parâmetros Curriculares Nacionais: Ensino } \\
\text { fundamental: ciências naturais }\end{array}$ & 6 \\
\hline
\end{tabular}


Rede 2 - Rede formada pelas referências

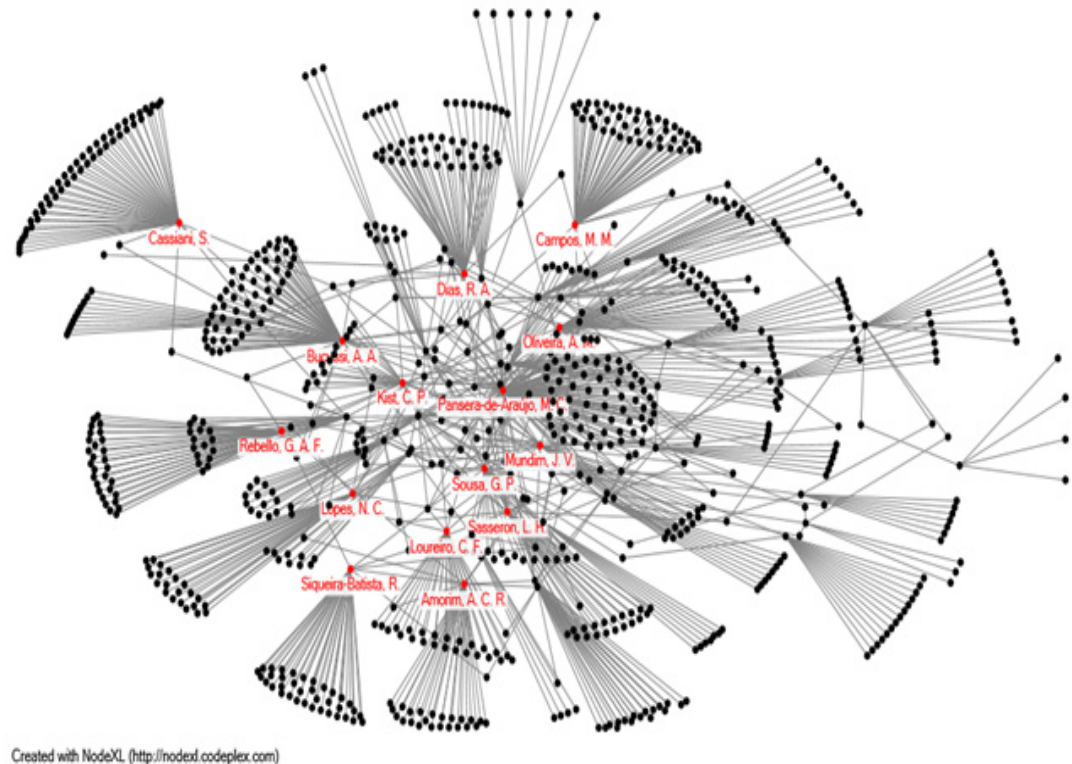

De acordo com a Tabela 3 é possível observar as obras e autores mais citados quando se busca pela representação da área biológica no campo de CTS. Por intermédio destes resultados, podemos destacar os referenciais que podem ser considerados de maior relevância para o tema em análise. Percebemos que Wildson Santos e Eduardo Mortimer aparecem como autores da obra mais citada com 13 citações: Uma análise de pressupostos teóricos da abordagem C-T-S (Ciência-Tecnologia-Sociedade). Os coautores possuem também a obra Tomada de decisão para a ação social responsável no ensino de ciências, bem como Santos e Schnetzler, são citados na obra Educação química: Compromisso com a cidadania, ambas com 7 citações cada. O levantamento também permite perceber o interesse dos autores dos artigos catalogados pelos Parâmetros Curriculares, tanto do ensino médio quanto do ensino fundamental. Na lista indicada, há apenas dois autores estrangeiros (Aikenhead e Fourez) e uma das obras mais citadas trata de metodologia de pesquisa: Pesquisa em Educação: abordagens qualitativas. Numa primeira análise, a temática Alfabetização Cientifica aparece com ênfase.. 
Comparando os resultados obtidos neste trabalho com os de um estudo realizado por Chrispino et al (2013), que analisou os 13 trabalhos mais citados como fontes de consulta na área de CTS, percebemos que os referenciais teóricos mais utilizados no universo de biologia/meio ambiente são distintos daqueles encontrados no estudo citado. Evidenciamos essa comparação a partir da exposição dos resultados de Chrispino et al. (2013, p. 464):

Estes vértices correspondem aos trabalhos listados a seguir, ordenados do mais citado para o menos citado entre os 13:

1. SANTOS, W. L. P.; MORTIMER, E. F. Uma análise de pressupostos teóricos da abordagem.C-T-S (Ciência-Tecnologia-Sociedade) no contexto da educação brasileira. Ensaio: Pesquisa em Educação em Ciências, Belo Horizonte, v. 2, n. 2, p. 105-115, 2002.

2. GONZÁLEZ GARCÍA, M. I.; LÓPEZ CEREZO, J. A.; LUJÁN LÓPEZ, J. L. Ciencia, tecnología y sociedad: una introducción al estudio social de la ciencia y la tecnología. Madrid: Tecnos, 1996.

3. AULER, D.; BAZZO, W. A. Reflexões para a implementação do movimento CTS no contexto educacional brasileiro. Ciência \& Educação, Bauru, v. 7, n. 1, p. 1-13, 2001.

4. AULER, D. Interações entre ciência-tecnologia-sociedade no contexto da formação de professores de ciências. 2002. 248 f. Tese. (Doutorado em Educação Científica e Tecnológica) - Universidade Federal de Santa Catarina, Florianópolis, 2002.

5. BAZZO, W. A. Ciência, tecnologia e sociedade e o contexto da educação tecnológica. Florianópolis: Ed. da UFSC, 1998.

6. BAZZO, W. A.; VON LINSINGEN, I.; PEREIRA, L. T. V. (Ed.). Introdução aos estudos CTS (ciência, tecnologia e sociedade). Madrid: Organização dos Estados Iberoamericanos para a Educação, a Ciência e a Cultura, 2003. (Cadernos de iberoamerica).

7. AULER, D.; DELIZOICOV, D. Ciência-tecnologia-sociedade: relações estabelecidas por professores de ciências. Revista Electrónica de Enseñanza de las Ciencias, Vigo, v. 5, n. 2, p. 337-355, 2006.

8. ACEVEDO DÍAZ, J. A. Cambiando la práctica docente en la enseñanza de las ciencias a través de CTS. Borrador, Huelva, v. 13, p. 26-30, 1996. 
9. AMORIM, A. C. R. O ensino de biologia e as relações entre ciência/ tecnologia/sociedade: o que dizem os professores e o currículo do ensino médio? In: ENCONTRO PERSPECTIVAS DO ENSINO DE BIOLOGIA, 6., 1997, São Paulo. Anais... São Paulo: USP, 1997. p. 74-77.

10. CRUZ, S. M. S. C.; ZYLBERSZTAJN, A. O enfoque ciência, tecnologia e sociedade e a aprendizagem centrada em eventos. In: PIETROCOLA, M. (Org.). Ensino de física: conteúdo e epistemologia numa concepção integradora. Florianópolis: Ed. da UFSC, 2001. p. 171-196.

11. SOLOMON, J. Teaching science, technology and society. Buckingham: Open University Press, 1993.

12. ACEVEDO DÍAZ, J. A. Educación tecnológica desde una perspectiva CTS: una breve revisión del tema. Alambique: Didáctica de las Ciencias Experimentales, Barcelona, v. 2, n. 3, p. 75-84, 1995.

13. AULER, D.; DELIZOICOV, D. Alfabetização científico-tecnológica para quê? Ensaio: Pesquisa em Educação em Ciências, Belo Horizonte, v. 3, n. 1, p. 105-115, 2001.

A análise comparativa dos dois resultados permite identificar apenas duas obras coincidentes: Uma análise de pressupostos teóricos da abordagem.C-T-S (Ciência-Tecnologia-Sociedade) no contexto da educação brasileira, de Santos e Mortimer, e Alfabetização científico-tecnológica para quê?, de Auler e Delizoicov. Desta forma, identifica-se uma particularidade da subárea de biologia: ela se apropria da abordagem CTS em suas pesquisas, porém, não utiliza de forma intensa as referências que são tidas como base comum na ampla área de Ensino CTS. Sendo assim, pode-se inferir que esta subárea apresenta o perfil de comunicação em rede singular: produz conhecimento utilizando-se de autores mais citados na grande área CTS (Santos, Mortimer, Delizoicov, Auler), mas utilizando-se de obras diferenciadas, bem como realça a participação de Teixeira na produção de conhecimento CTS no Ensino de Biologia. Isso torna a biologia e seu viés ambiental dentro de CTS um grupo com características singulares.

É importante destacar que a pesquisa se deu a partir de um Banco de Dados estabelecido pelo Grupo CTS e Educação, do Cefet/RJ, porém este é o primeiro trabalho dedicado à área da biologia realizada a partir desses dados. Assim, apesar de o Banco de Dados ser composto pelas principais revistas da 
área de ensino de ciências e de CTS, não se pode deixar de considerar o fato de que não foram incluídas na pesquisa as publicações das revistas dedicadas especificamente ao ensino de biologia. Por sua vez, os resultados obtidos neste trabalho devem considerar tal questão.

\section{Considerações Finais}

Analisar as palavras-chave e os referenciais teóricos pode contribuir para melhorar a compreensão da base conceitual dos trabalhos da abordagem de CTS no Ensino de Biologia e fornecer uma ampla visão a respeito de como a biologia vem sendo representada em CTS, favorecendo a gestão do conhecimento na e sobre a área. No presente estudo foi possível verificar que, diferentemente do esperado, a biologia, apesar de abordar CTS e seus temas, não faz uso dos referenciais teóricos que são propriamente comuns na área. Desta forma, esta subárea constitui um perfil particular com referenciais próprios, apresentando uma rede de comunicação específica, mais restrita.

Como resultado geral, sugerimos que os trabalhos aqui referenciados, sendo os mais citados no campo estudado, podem servir de fonte inicial de leitura para os interessados na área, na medida em que fornecem um panorama bem diversificado em relação as suas propostas de investigação dentro da abordagem de CTS.

Por sua vez, para uma melhor compreensão da representatividade da biologia na área de CTS, uma nova análise deverá ser feita, na medida em que as principais revistas voltadas ao ensino de biologia estiverem inseridas dentro do Banco de Dados do Grupo CTS e Educação, do Cefet/RJ. Esperamos que uma eventual pesquisa, considerando tais revistas, poderá resultar em um corpus documental maior de artigos selecionados, trazendo informações novas e importantes para complementar esta análise.

Acreditamos que inserir conceitos da educação de CTS e CTSA nas disciplinas já existentes seja de suma importância para uma formação de cidadãos críticos e capazes de tomar decisões responsáveis. Essas referências, efetivamente, vão buscar uma transformação na ordem das crenças e da produção da 
subjetividade no âmbito da ecologia. Em suas ideias, Santos (2007) complementa tal pensamento ao afirmar a relevância de promover tal inovação curricular no sentido do desenvolvimento de uma formação contínua com adoção de reflexões críticas sobre o contexto da sociedade tecnológica vivida por todos nós. Desta forma, não se trata de simplificar currículos, mas resignificá-los para que, de fato, sejam agentes de transformação social numa educação problematizadora. Logo, podemos entender que tais acrônimos representam um processo educacional com poder de transformação em diversos aspectos, sejam eles sociais, políticos, históricos, axiológicos ou econômicos.

Em Chrispino et al. (2013) encontramos a necessidade de tornar a área de estudos de CTS interdisciplinar e contextualizada, posto que nenhuma tecnologia é neutra e constrói a sociedade rumo a um determinado caminho. Entender a complexidade das relações entrelaçadas entre ciência, tecnologia e sociedade possibilita visualizar determinada questão de vários ângulos e retroalimenta essa própria relação, formando uma sociedade que pensa, inventa, executa, analisa seus efeitos e pensa novamente. Este ciclo proporciona uma renovação no ensino de ciência, visando à democratização do saber para o indivíduo construir uma atitude ante a CTS, de acordo com seus valores e tradição.

Ao citar anteriormente a questão da não neutralidade da ciência e da tecnologia, áreas que se entrelaçam e se desenvolvem de forma independente e concomitante, Pinch e Bijker (2008), ao realizarem uma análise da história da evolução dos variados modelos de bicicleta sob um enfoque de contribuição mútua entre essas duas áreas, estabelecem etapas para se obter soluções em Ciência e Tecnologia no desenvolvimento de aparatos. Primeiramente, identifica-se o grupo social de interesse relevante; após, estudam-se os problemas que esse grupo apresenta com o artefato. Em um terceiro momento, analisam-se as possíveis soluções (tecnológicas, morais, econômicas, etc.) para adequar o público-alvo ao produto. A importância de tal referência para este trabalho se faz na exemplificação de uma desconstrução linear no desenvolvimento de qualquer invenção tecnológica. Logo, não há um modelo linear, e sim multidirecional. A construção social da tecnologia proposta por 
esses autores propõe que a produção de um artefato resulta de negociações sociais, ou seja, das diferentes interações entre os grupos sociais com o aparato tecnológico.

Nortear o aluno neste sentido, fazendo com que alcance uma visão multifacetada e postura menos ingênua da construção da ciência e da tecnologia, também é um papel da Natureza da Ciência ${ }^{5}$ na preparação do indivíduo. Este passa a adquirir melhor compreensão da ciência e de suas implicações nas relações entre ciência, tecnologia e sociedade. Segundo Praia, Gil-Pérez e Vilches (2007), há a necessidade de uma alfabetização científica que permita preparar de forma substancial o cidadão, servindo de fonte para coerentes tomadas de decisão. Essa orientação leva em conta a visão distorcida da Natureza da Ciência que, em muitos casos, retrata o trabalho científico como uma prática descontextualizada e distante de interesses.

Pretende-se, assim, fomentar a alfabetização científica e tecnológica dos cidadãos por intermédio de uma certa imersão na cultura científica e tecnológica, fundamental para a formação de cidadãos e cidadãs críticos que, no futuro, participarão na tomada de decisões... (PRAIA; GIL-PÉREZ; VILCHES, 2007, p. 152).

Os trabalhos mais referenciados na área biológica/ambiental mostraram o caráter educacional no que diz respeito à conscientização ambiental. A maioria, de certa forma, relatou a utilização de conceitos ligados à CTS/ CTSA para gerar o conhecimento da disciplina em questão. Nesses casos relatados, o processo de ensino-aprendizagem parece ter acontecido de forma mais contextualizada e satisfatória para os envolvidos em cada situação, suscitando o diálogo e as diferentes visões de uma mesma questão. Conforme Auler (2007):

5 Acevedo et al. (2005) sugerem que a aprendizagem da Natureza da Ciência constitui-se em um dos principais objetivos do ensino das ciências, em concordância com Hodson (1994). 
Considera-se fundamental superar a concepção de que o tempo presente é tempo de preparação para etapas futuras, para vivências futuras, para exames futuros. A anulação do presente, enquanto espaço-tempo de significação, a não vivência do presente, sendo a satisfação jogada para o futuro, gera frustração, desmotivação, culminando com o abandono, com a evasão (AULER, 2007, p. 15).

Nesse sentido, o tempo do aprender e o tempo do viver são concomitantes, pois a aprendizagem se realiza na experiência em que cada um e o coletivo se veem implicados na produção do conhecimento. Esse é o desafio de cada professor, de cada escola e de cada educando, assim como da população em geral, posto que a construção de novos parâmetros para a vida depende de uma ação cotidiana de todos.

\section{Referências}

ACEVEDO, J. A. et al. Mitos da didática das ciências acerca dos motivos para incluir a natureza da ciência no ensino de ciências. Ciência \& Educação, vol. 11, n. 1, p. 1-15, 2005.

ACEVEDO, J. A.; VÁSQUEZ, A.; MANASSERO, M. A. Papel de la Educación CTS en una Alfabetización Científica y Tecnológica para todas las Personas. Revista Electrónica de Enseñanza de las Ciencias, v. 2, n. 2, 2003.

ANDRADE, B. dos S.; VASCONCELOS, C. A. O enfoque CTSA no Ensino Médio: um relato de experiência no ensino de Biologia. Scientia Plena, vol. 10, n. 4, 2014.

AULER, D. Enfoque Ciência-Tecnologia-Sociedade: pressupostos para o contexto brasileiro. Ciência \& Ensino, vol. 1, n. especial, 2007.

CHRISPINO, A. et al. A área CTS no Brasil vista como rede social: onde aprendemos? Ciência \& Educação, 19(2), p. 455-479, 2013.

GRÜN, M. Ética e educação ambiental: a conexão necessária. 14. ed. São Paulo: Papirus, 2011.

MATHEUS, R. F.; SILVA, A. B. de O. Análise de redes sociais como método para a Ciência da Informação. DataGramaZero-Revista de Ciência da Informação, 7(2), p. 1-26, 2006. 
PINCH, T. J.; BIJKER, W. E. La construcción social de hechos y de artefactos: o acerca de cómo la sociologia de la ciencia y la sociología de la tecnología pueden beneficiarse mutuamente. In: THOMAS, Herán; BUCH, Alfonso. Actos, actores y artefactos. Bernal (AR): Universidad Nacional de Quilmes, 2008.

PRAIA, J.; GIL-PÉREZ, D.; VILCHES, A. O papel da natureza da ciência na educação para a cidadania. Ciência \& Educação, v. 13, n. 2, p. 141-156, 2007.

SANTOS, M. E. V. M. As diferentes correntes epistemológicas e suas implicações para a pesquisa em educação ambiental. Pesquisa em Educação Ambiental, vol. 2, n. 1, p. 67-94, 2007.

SANTOS, W. L. P. dos. Contextualização no ensino de ciências por meio de temas CTS em uma perspectiva crítica. Ciência \& Ensino, vol. 1, n. especial, 2007.

TOLEDO, C. E. R. et al. Os temas de pesquisa que orbitam o enfoque CTS: uma análise de rede sobre as teses publicadas no Brasil. Indagatio Didactica, v. 8, n. 1, 2016.

VON LINSINGEN, I.; CASSIANI, S. Educação CTS em perspectiva discursiva: contribuições dos estudos sociais da ciência e da tecnologia. Redes (Bernal), vol. 16, p. 163-182, 2011.

VON LINSINGEN, I. Perspectiva educacional CTS: aspectos de um campo em consolidação na América Latina. Ciência \& Ensino, vol. 1, n. especial, 2007.

Recebido em: $1 \% 2 / 2017$

Aceito em: $15 / 7 / 2017$ 